\title{
Postoperative hypoparathyroidism - what the family doctor should know
}

\author{
PATRYCJA NOWICKA-STAZŻKA ${ }^{A-F}$, JOANNA ELŻBIETA MALICKA A, D, E, JERZY S. TARACH ${ }^{A, D, ~ E}$
}

Department of Endocrinology, Medical University of Lublin, Poland

A - Study Design, B - Data Collection, C - Statistical Analysis, D - Data Interpretation, E - Manuscript Preparation, F - Literature Search, G - Funds Collection

Summary Background. Hypoparathyroidism is a condition of parathyroid hormone (PTH) deficiency, which can be inherited, but it is also encountered mainly after thyroid or parathyroid gland surgery. PTH stimulates calcium reabsorption in the kidneys and calcium release from the bones. It also stimulates renal production of 1,25-dihydroxyvitamin D (calcitriol) from 25-hydroxyvitamin D. Hypocalcaemia caused by PTH deficiency can lead to cramping and twitching of the muscles or tetany and many other symptoms.

Objectives. The aim of the study was to retrospectively evaluate, in own material, the prevalence and clinical picture of hypoparathyroidism, caused by various surgical procedures performed on the thyroid gland.

Material and methods. The study group involved 145 patients after thyroid surgery, treated for various reasons in the Department of Endocrinology of the Medical University in Lublin in the years 2000-2017. The authors analyzed the medical histories and clinical pictures of the patients and the results of laboratory tests, including calcium, phosphorus and PTH concentrations.

Results. 32 patients were diagnosed with hypoparathyroidism, and 113 patients without calcium concentration disorders. The analyzed groups did not differ significantly in respect to gender, age and indications for thyroid surgery. We found no correlation between the length of follow up and PTH concentration, a weak negative correlation with total calcium concentration and a quite strong negative correlation with ionized calcium concentration in the subgroup with newly diagnosed hypoparathyroidism.

Conclusions. The clinical picture of hypocalcaemia varies, and it is important to take into account the possibility of hypoparathyroidism in a patient after thyroid surgery.

Key words: hypoparathyroidism, hypocalcaemia, tetany, thyroid operation.

Nowicka-Stążka P, Malicka JE, Tarach JS. Postoperative hypoparathyroidism - what the family doctor should know. Fam Med Prim Care Rev 2017; 19(3): 247-250, doi: https://doi.org/10.5114/fmpcr.2017.69286.

\section{Background}

Hypoparathyroidism is a condition of parathyroid hormone (PTH) deficiency, which can be inherited, but it is also encountered mainly after thyroid or parathyroid gland surgery. It can also be caused by the autoimmune process (e.g. in autoimmune polyglandular syndrome 1 - APS-1), as well as by a number of other reasons. PTH stimulates calcium reabsorption in the kidneys and calcium release from the bones. It also stimulates renal production of 1,25-dihydroxyvitamin $D$ (calcitriol) from 25 -hydroxyvitamin D. 1,25-dihydroxyvitamin $\mathrm{D}$ is the most active form of vitamin $D$, and it acts on the gastrointestinal tract to increase calcium absorption [1]. In the absence of adequate PTH activity, bone resorption, the phosphaturic effect, renal distal tubular calcium reabsorption and 1,25-dihydroxyvitamin D-mediated dietary calcium absorption cannot occur. Therefore, the result of PTH deficiency is hypocalcaemia, meaning that the ionized calcium concentration in the extracellular fluid falls below the reference range. This can lead to cramping and twitching of muscles or tetany (involuntary muscle contraction) and many other symptoms. Patients with hypocalcaemia often complain of numbness and a tingling in their fingertips, toes and the perioral region. Paresthesias of the extremities may occur, along with fatigue and anxiety. Clinically, neuromuscular irritability can be demonstrated by eliciting Chvostek's or Trousseau's signs. Acute hypocalcaemia may have cardiac manifestations - prolongation of the QT-interval and abnormal T-waves mimicking myocardial infarction [2].

Chronic hypocalcaemia may have an entirely different presentation. Grand mal, petit mal or focal seizures have been de- scribed. Increased intracranial pressure and papilledema may be present. Epidermal changes include dry skin, coarse hair and brittle nails. If hypocalcaemia has occurred prior to the age of 5 , dental abnormalities (enamel hypoplasia, defects in dentin, shortened premolar roots, thickened lamina dura, delayed tooth eruption and an increase in the number of dental caries) may be present. Alopecia following surgically-induced hypoparathyroidism has been noted, but this can be also associated with autoimmune hypoparathyroidism. Other skin lesions reported in patients include atopic eczema, exfoliative dermatitis, impetigo herpetiformis and psoriasis. Restoration of normocalcaemia is reported to improve these skin disorders. In the elderly population, disorientation or confusion may be present [3].

Changes in smooth muscle function caused by hypocalcaemia may induce irritability of the autonomic ganglia, resulting in dysphagia, abdominal pain, biliary colic, wheezing and dyspnea. In some cases of chronic hypoparathyroidism, psychoses, organic brain syndrome and subnormal intelligence have been observed.

\section{Objectives}

The aim of the present study was to retrospectively evaluate, in own material, the prevalence and clinical picture of hypoparathyroidism caused by various surgical procedures performed on the thyroid gland.

\section{Material and methods}

The study group involved 145 patients after thyroid surgery (129 women, i.e. $88.96 \%$ of the group, and 16 men, i.e. $11.03 \%$ ), 
aged $20-88$ years (median 63), treated for various reasons in the Department of Endocrinology of the Medical University of Lublin in the years 2000-2017.

The authors analyzed the medical histories and clinical pictures of the patients and the results of laboratory tests, including calcium, phosphorus and PTH concentrations.

The obtained results were analyzed statistically. Values measured in a nominal scale were characterized using count and percentage, while in a ratio scale using mean value and standard deviation. Variables with normal distribution (calcium concentration) and skew distribution (time between thyroid surgery and the diagnosis of hypoparathyroidism and between surgery and hospitalization; age) were evaluated using the Shapiro-Wolf test. The chi-square test was used to evaluate the differences between the analyzed groups. A significance level of $p<0.05$, indicating the presence of statistically significant differences or dependencies, was accepted. The correlation between the two parameters was analyzed using the Pearson correlation test.

\section{Results}

32 patients ( $2 \mathrm{M}, 30 \mathrm{~F} ; 22.1 \%$ of the entire group) were diag nosed with hypoparathyroidism (HPTH), and 113 patients (14 M, $99 \mathrm{~F} ; \mathbf{7 7 . 9 \%}$ of the entire group) without calcium concentration disorders (nHPTH). Among 32 HPTH patients, 2 were admitted from the emergency ward due to their first episode of tetany.

In the HPTH group, hypoparathyroidism was most often observed after thyroid cancer operation $(45.5 \% ; n=5)$. Graves' disease, a toxic multinodular goiter and a goiter with compression symptoms caused this complication in $31.3 \%(n=5), 21.4 \%(n=3)$ and $18.2 \%(n=19)$, respectively (Table 1$)$.

\begin{tabular}{|c|c|c|c|c|}
\hline & $\begin{array}{l}\text { Goiter } \\
\text { with com- } \\
\text { pression }\end{array}$ & $\begin{array}{l}\text { Toxic mul- } \\
\text { tinodular } \\
\text { goiter }\end{array}$ & $\begin{array}{l}\text { 'Graves' } \\
\text { disease }\end{array}$ & $\begin{array}{l}\text { Thyroid } \\
\text { cancer }\end{array}$ \\
\hline $\begin{array}{l}\text { Hypoparathy- } \\
\text { roidism (\%) }\end{array}$ & $\begin{array}{l}18.2 \\
(n=19)\end{array}$ & $\begin{array}{l}21.4 \\
(n=3)\end{array}$ & $\begin{array}{l}31.3 \\
(n=5)\end{array}$ & $\begin{array}{l}45.5 \\
(n=5)\end{array}$ \\
\hline
\end{tabular}

\section{Non-hypoparathyroidism}

$$
\begin{array}{ll}
\square \text { Goiter with compression } & \square \text { Toxic multinodular goiter } \\
\square \text { Graves' disease } & \square \text { Thyroid Cancer }
\end{array}
$$

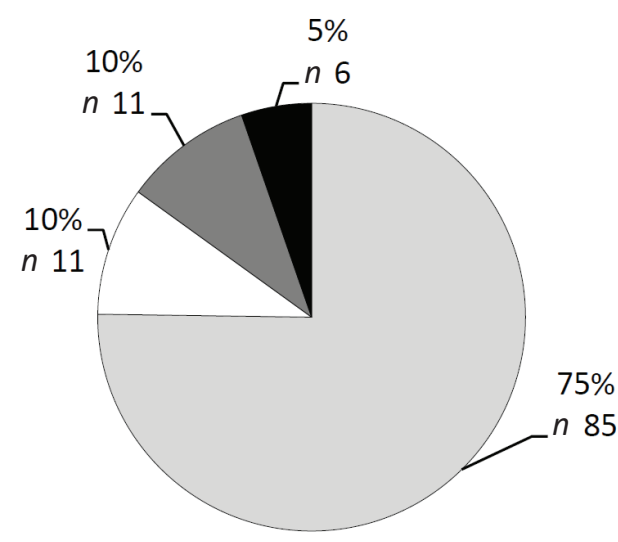

Figure 1. Indications for thyroid surgery in the nHPTH group

The analyzed groups did not differ significantly in respect to gender, age and indications for thyroid surgery (Figure 1, 2). In the HPTH group, the age of patients ranged between $26-76$ years (median 60), and in the nHPTH group, between $20-88$ years (median 65 ). The time elapsed between thyroid operation and di- agnosis of hypoparathyroidism ranged from 3 days to 15 years and, in the case of people admitted from the emergency ward, from 3 days to 11 months. In the nHPTH group, the time interval between surgery and hospitalization was 18 days -40 years. The mean PTH concentration was $7.0 \mathrm{pg} / \mathrm{ml}$ (normal range: 14-72 $\mathrm{pg} / \mathrm{ml}$ ) in the HPTH group and $52 \mathrm{pg} / \mathrm{ml}$ in the nHPTH group, while the mean calcium concentration was $8.7 \mathrm{mg} / \mathrm{dl}$ and 9.5 $\mathrm{mg} / \mathrm{dl}$, respectively (normal range: $8.7-10.4 \mathrm{mg} / \mathrm{dl}$ ). In the subgroup admitted from the emergency ward, the mean calcium concentration was $6.6 \mathrm{mg} / \mathrm{dl}$. We found no correlation between the length of follow up and PTH concentration in any of the analyzed groups, and there was only a weak negative correlation $(-0.29)$ with total calcium concentration and a quite strong negative correlation $(-0.86)$ with ionized calcium concentration in the subgroup with newly diagnosed hypoparathyroidism.

\section{Hypoparathyroidism}

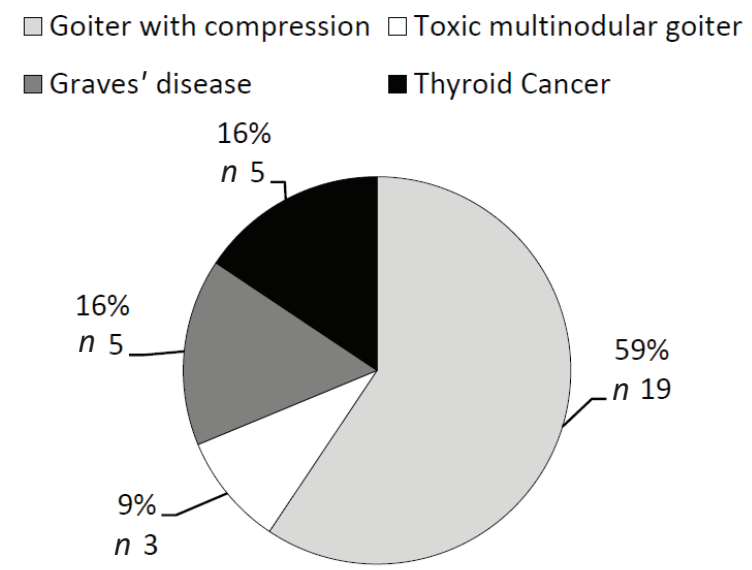

Figure 2. Indications for thyroid surgery in the HPTH group

\section{Discussion}

Parathyroids are small endocrine glands of lentil grain size, usually totaling four in number, located on the posterior surface of the thyroid gland. Rarely they may be located inside the thyroid, in the mediastinum or even inside the thymus.

Thyroid surgery is frequently performed for various indications: suspicion of cancer, goiter with a compression of the trachea or esophagus (causing dyspnoea, hoarseness or difficulty in swallowing), visible or unsightly mass on the neck, or when a goiter is causing symptoms due to the overproduction of thyroid hormones (toxic nodular goiter or Graves' disease). The extent of thyroid surgery can be generally classified as partial or total. Recommendations concerning the extent of an operation are determined by the reasons for surgery. A hemithyroidectomy may be recommended in the case of a toxic solitary nodule or benign one-sided nodules that are causing local compression symptoms. A total or near-total thyroidectomy may be advised for patients with Graves' disease, because it removes target tissue for the thyroid-stimulating hormone receptor antibodies. Such a procedure is also recommended in a large multinodular goiter. A subtotal thyroidectomy leaves a thyroid remnant and is therefore less likely to cause complications; however, it can often cause recurrences of hyperthyroidism, requiring re-operations [4]. There is also the possibility that a subtotal thyroidectomy, which is thought to be somewhat safer than a total thyroidectomy, may leave an undetected thyroid cancer in place [5]. In the case of papillary cancer, a total or near-total thyroidectomy with subsequent treatment with radioactive iodine is recommended by most surgeons as the treatment of choice. Such recommendations also refer to the treatment of follicular thyroid cancer confirmed by a histopathological examination. 
Potential major complications of thyroid surgery include bleeding, injury of the superior or recurrent laryngeal nerve, hypoparathyroidism, thyrotoxic storm and infection. Because the parathyroid glands are usually located close to the thyroid and share the blood supply and lymphatic drainage, thyroid surgery may affect them. Hypoparathyroidism can result either from direct trauma to the parathyroid glands, or devascularization, or removal of the glands during surgery. Postoperative hypoparathyroidism with subsequent hypocalcaemia can be persistent or transient, and in most cases, it is initially asymptomatic.

The risk of hypocalcaemia is higher after a total thyroidectomy or total thyroidectomy with node dissection [6], and in a transient form, it was observed in $16-55 \%$ of total thyroidectomies [6, 7], more frequently in Graves' disease than a nontoxic multinodular goiter, although the incidence of permanent hypoparathyroidism didn't differ between these groups [8].

In our material, hypoparathyroidism was most often caused by a total thyroidectomy due to thyroid cancer ( $45.5 \%$ of cancer operations were complicated by hypoparathyroidism). In relation to Graves' disease and a toxic multinodular goiter, this complication occurred with a frequency of $31.3 \%$ and $21.4 \%$, respectively. Interestingly, hypoparathyroidism was less frequent among patients operated on with a multinodular euthyroid goiter with local compression symptoms and raised only $18.2 \%$.

Our observation, that the greater the range of surgery, the greater the probability of hypoparathyroidism, is similar to the opinion presented by other researchers. In two large metaanalyses concerning the complications of a total and subtotal thyroidectomy in Graves' disease, a total thyroidectomy was associated with an increase in both temporary and permanent hypoparathyroidism [9]. Barczyński et al. [10], in a prospective study including patients operated on due to a multinodular goiter, recurrent hypoparathyroidism was most often observed in individuals after a total thyroidectomy compared to less extensive procedures. On the other hand, other authors didn't observe a relationship between the extent of surgery and permanent or transient hypoparathyroidism among patients with Graves' disease [11].
In our opinion, it seems that the incidence of complications may be more relevant to the surgeon's experience than to the extent or indications for surgery.

The latency between surgery and the diagnosis of hypoparathyroidism in our study ranged from 3 days to 15 years, and in the subgroup admitted from the emergency ward, it was 3 days to 11 months. Patients with iatrogenic hypoparathyroidism usually present with tetany occurring within a few weeks from the thyroidectomy. However, the clinical presentation of hypoparathyroidism can be less obvious and much delayed. The first manifestation may present as movement disorders, such as chorea, symptoms of increased intracranial pressure or epileptic seizures [12-14]. Time intervals from surgery to first seizures up to 61 years were reported in single cases [15-17].

Family physicians play a key role in the process of diagnosis and management of hypoparathyroidism. Suspicion of hypocalcaemia requires a differential diagnosis - examining the patient's neck for any sign of thyroid surgery may be useful [18], followed by calcium and vitamin D metabolite supplementation. Treatment can be further enhanced by introducing thiazide diuretics, which decrease urinary calcium excretion by increasing distal renal tubular calcium reabsorption. Combining diuretics with a low-salt, low-phosphate diet and phosphate binders is beneficial.

\section{Conclusions}

Many patients who are under the care of family doctors undergo thyroid surgery for various reasons. It is crucial to remember that hypoparathyroidism can be one of the most common and more serious complications of such operations, and its clinical presentation can be distant in time. The clinical picture of hypocalcaemia can vary greatly from patient to patient, and it is important to take into account the possibility of hypoparathyroidism in a patient after thyroid surgery. This mainly depends on the general practitioner and how quickly the diagnosis is made and the appropriate treatment is implemented.

Source of funding: This work was funded by the authors' resources. Conflict of interest: The authors declare no conflict of interests.

\section{References}

1. Cooper MS, Gittoes NJ. Diagnosis and management of hypocalcaemia. BMJ 2008; 336(7656): 1298-1302.

2. Rallidis LS, Gregoropoulos PP, Papasteriadis EG. A case of severe hypocalcaemia mimicking myocardial infarction. Int J Cardiol 1997; 61(1): 89-91.

3. Schafer AL, Shoback DM. Hypocalcemia: diagnosis and treatment. www.Endotext.org [Internet] 2016 Jan [cited 20.03.2017]. Available from URL: https://www.ncbi.nlm.nih.gov/books/NBK279022/.

4. Liu ZW, Masterson L, Fish B, et al. Thyroid surgery for Graves' disease and Graves' ophthalmopathy. Cochrane Database Syst Rev 2015; 11: CD010576, doi: 10.1002/14651858.CD010576.pub2.

5. Cirocchi R, Trastulli S, Randolph J, et al. Total or near-total thyroidectomy versus subtotal thyroidectomy for multinodular non-toxic goitre in adults. Cochrane Database Syst Rev 2015; 8: CD010370, doi: 10.1002/14651858.CD010370.pub2.

6. Sitges-Serra A, Ruiz S, Girvent M. Outcome of protracted hypoparathyroidism after parathyroidectomy. Br J Surg 2010; 97(11): 1687$-1695$.

7. Page C, Strunski V. Parathyroid risk in total thyroidectomy for bilateral, benign, multinodular goitre: report of 351 surgical cases. J Laryngol Otol 2007; 121: 237-241.

8. Welch KC, McHenry CR. Total thyroidectomy: is morbidity higher for Graves' disease than nontoxic goiter? J Surg Res 2011; 170(1): 96-99.

9. Feroci F, Rettori M, Borrelli A, et al. A systematic review and meta-analysis of total thyroidectomy versus bilateral subtotal thyroidectomy for Graves' disease. Surgery 2014; 155(3): 529-540.

10. Barczyński M, Konturek A, Hubalewska-Dydejczyk A, et al. Five-year follow-up of a randomized clinical trial of total thyroidectomy versus Dunhill operation versus bilateral subtotal thyroidectomy for multinodular nontoxic goiter. World J Surg 2010; 34(6): $1203-1213$.

11. Guo Z, Yu P, Liu Z, et al. Total thyroidectomy vs bilateral subtotal thyroidectomy in patients with Graves' diseases: a meta-analysis of randomized clinical trials. Clin Endocrinol 2013; 79(5): 739-746.

12. Steinberg H, Waldron BR. Idiopathic hypoparathyroidism. Medicine (Baltimore) 1952; 31(2): 133-154.

13. Fonseca OA, Calverley JR. Neurological manifestations of hypoparathyroidism. Arch Intern Med 1967; 120(2): 202-206.

14. Dimich A, Bedrossian PB, Wallach S. Hypoparathyroidism - clinical observations in 34 patients. Arch Intern Med 1967; 120(4): 449-458.

15. Lehmann JB, Leidy JW. A post-thyroidectomy convulsion: an unusual presentation of chronic hypoparathyroidism. V Med J 1994; 90(10): 420-421. 
16. Reddy ST, Merrick RD. Hypoparathyroidism, intracranial calcification, and seizures 61 years after thyroid surgery. Tenn Med 1999; $92(9)$ : 341-342.

17. Halperin I, Nubiola A, Vendrell J, et al. Late onset hypocalcemia appearing years after thyroid surgery. J Endocrinol Invest 1989; 12(6): 419-420.

18. Ruchała M, Szczepanek E. Choroba guzkowa tarczycy. Fam Med Prim Care Rev 2008; 10(4): 1383-1392 (in Polish).

Tables: 1

Figures: 2

References: 18

Received: 31.03.2017

Revised: 04.04.2017

Accepted: 10.04.2017

Address for correspondence:

Patrycja Nowicka-Stążka, MD, PhD

Klinika Endokrynologii SPSK4

ul. Jaczewskiego 8

20-954 Lublin

Polska

Tel.: + 4881 724-46-68

E-mail: pat_nowicka@o2.pl 